\title{
Energy-saving analysis of grey water heat recovery systems for student dormitory
}

\author{
Joanna Paduchowska ${ }^{1, *}$, Alina Żabnieńska-Góra ${ }^{1}$, and Iwona Polarczyk $^{1}$ \\ ${ }^{1}$ Wroclaw University of Science and Technology, Faculty of Environmental Engineering, \\ Wybrzeze Wyspianskiego 27, 50-370 Wroclaw, Poland
}

\begin{abstract}
Grey water heat recovery (GWHR) is one of the significant opportunities for energy savings in student dormitories and seeks to meet the EU environmental strategy. This article performs the results of temperature and flow rate measurements carried out for domestic hot water consumption for two student dormitories in Wroclaw. An energy analysis was carried out for the measurement data with and without circulation system to assess the energy savings from grey water. Results ensure that GWHR system allows to save $53 \%$ of the energy in these buildings.
\end{abstract}

\section{Introduction}

More than 504 student dormitories serve for over than 136,905 students in Poland. Theoretically, it gives 5476200 litres of DHW per day and the same amount of wastewater is discharged directly into the sewerage system, which results in large energy losses. GWHR leads to energy savings from the used DHW in student dormitories. Many technologies are available, e.g. using only a heat exchanger [1] or only a heat pump [2] or hybrid energy systems of heat exchanger [1], solar applications and heat pumps for residential buildings and district heating [3-5]. Currently advanced heat pump technology technologies can be used in different energy sectors [6].

However, GWHR using a heat pump brings the best results and facilities where there is a sufficiently large flow rates of this sewage. In the case of a small flow rates of GW, it is advisable to use only the exchanger itself. Cost effectiveness analysis of each energy system should be determined individually for each case of building. In buildings with significant amounts of DHW, energy is lost in warm GW discharged into the sewage system. The cost of heat irretrievably lost along with sewage discharged to the sewer can go up to tens or even hundreds of thousands of zlotys. In order to estimate these energy savings from sewage discharged water, the temperature and the DHW consumption should be determined from in the building, to assume the appropriate heat recovery system [4].

European Parliament Directive 2018/844 of the EU Council of 30 May 2018 [7] amending Directive 2010/31/EU concerned with the energy performance of buildings (EPBD) and Directive 2012/27/EU on energy efficiency (EED) of 19 June 2018 emphasises the development of long-term strategies based on national action plans for the decarbonisation of construction resources and the widespread use of intelligent

*Corresponding author: joanna.paduchowska@pwr.edu.pl 
technologies and automation in buildings. These actions will achieve the objectives of the climate package.

In Poland, the share of unconventional energy in total energy consumption is growing year on year, but coal is still the main source of energy for district heating systems and DHW. From this point of view, GW should not only be seen as a problem but as an opportunity to recover significant amounts of waste heat energy, which can be effectively recovered and used to heat domestic water and heat indoor spaces. In summer it can be used as a cold source of energy for air conditioning [8].

Energy recuperated from GW can be utilized in the same buildings from which this medium is removed. The use of a GW heat recovery system is, therefore, one of the steps to implement the provisions of the above directive and makes it possible to significantly reduce dependence on the availability of fossil fuels and on weather conditions. The use of appropriate technology (heat exchangers and heat pumps) in student dormitories together with a building automation system will enable the transition to a more sustainable energy supply, thus supporting the strategy for heating and cooling as well as DHW preparation. Weaknesses and strengths of GW heat recovery system in student dormitory are discussed in the SWOT analysis on Fig. 1.

\section{Heat recovery in students dormitory}

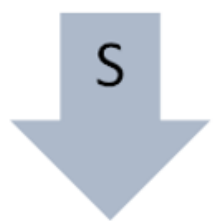

Strengths

- possibility of using grey water as a heat source for DHW

- high GW flow rates

- possibility of using technical solutions adapted to local conditions (heat pump, heat exchanger)

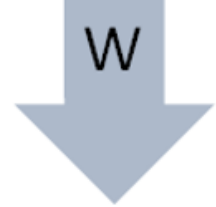

Weaknesses

- fluctuations in temperature and flow rates of GW

- lack of operational experience

-limited grey water temperature range
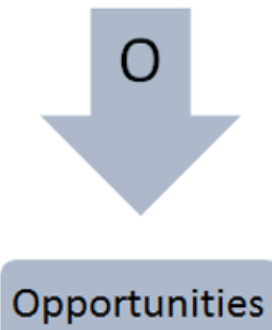

- development of new engineering designs for heat recovery systems

- reduction of energy demand for DHW system

-possibility of reducing the use of fossil fuels

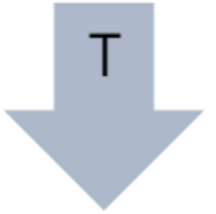

Threats

- lack of approval from potential users

- negative effects in sewage treatment plant (lower temperature) -technological weaknesses

Fig. 1. SWOT analysis of exploiting GWHR systems. 


\section{Analysis of the measurements carried out with and without circulation system}

\subsection{Scale of DHW consumption}

The share of DHW consumption in relation to the total cold water consumption is $30-45 \%$ in general [9]. According to Polish standards total water consumption for student dormitories per day is $100 \mathrm{l} /$ person, which gives about $40 \mathrm{l}$ /day of DHW per student [10].

The results of measurements in the student's dormitories in Poland shows that water consumption per day during the year amounted $451 /$ person on average [11]. In other countries the value of DHW consumption per student in a student dormitory is between 30 and $501 /$ day [12].

DHW consumption and the number of people in the building influence the amount of GW discharged. Application of GWHR in student residences brings both economic and environmental benefits. These savings will be greater for buildings with large DHW consumption.

\subsection{Performance of the measurements carried out}

The dormitories where the measurements carried out in two buildings T-15 (476 people) and T-16 (600 people) located at Wittiga Street in Wroclaw.

The buildings have ten residential floors each. In total there are 120 residential modules with bathrooms. There is no circulation installation in the T-16 building, which may influence the DHW consumption. In addition, the measured temperature after the DHW heat exchanger is too low. The specification of measured parameters in these buildings are presented in Table 1. This measurements were taken with the use of three non-invasive devices, with high measurement accuracy $( \pm 1.0 \%)$, as follow:

1. Portable ultrasonic flow meter FLUXUS F601 provided by Flexim,(DN 10 to DN 400, -30 to $+130^{\circ} \mathrm{C}$ )

2. Portable ultrasonic flow meter Portaflow C provided by Fuji, (DN 13 to DN 400, -40 to $+100^{\circ} \mathrm{C}$ )

3. Wireless temperature measurement platform provided by Wisensys, $\left(-50\right.$ to $\left.+150^{\circ} \mathrm{C}\right)$

Table 1. Measured parameters for buildings T-15 and T-16.

\begin{tabular}{|c|c|c|c|}
\hline Parameter & T15 & T16 & Unit \\
\hline Average daily hot water consumption per person & 61 & 77 & $1 /$ per-day \\
\hline Maximum flow rate & 5.5 & 5.53 & $\mathrm{~m}^{3} / \mathrm{h}$ \\
\hline Average DHW temperature in the heat source & 50.5 & 50.2 & ${ }^{\circ} \mathrm{C}$ \\
\hline
\end{tabular}

Measurements of DHW consumption in buildings T-15 and T-16 were carried out from 04.2013 to 07.2013 according to the actual diagram (Fig. 2). In order to check the average DHW consumption, public holidays and days off are excluded from the measurement data in order to assume with the greatest probability that the number of people in the building is equal to the theoretical number of people accommodated. Thus, the measurements were presented for selected period which corresponds to data from the literature, which shows 
that cleaning works before the summer break start in June. Therefore, the largest amount of domestic hot water is used during this time [13].

Figure 3 shows the unit daily DHW consumption per person for selected days. Figures 4 and 5 show the distribution of instantaneous flows for both buildings under analysis, while Figure 6 shows the DHW temperature on the outlet of the DHW heat exchanger.

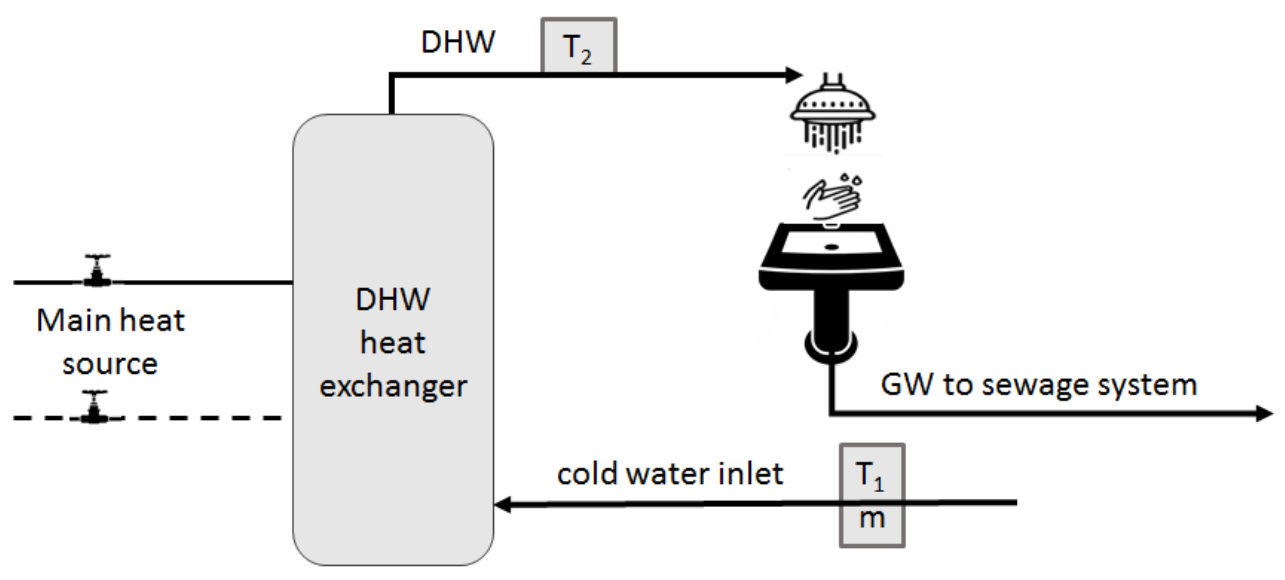

Fig. 2. Scheme of DHW system in buildings T-15 and T-16.

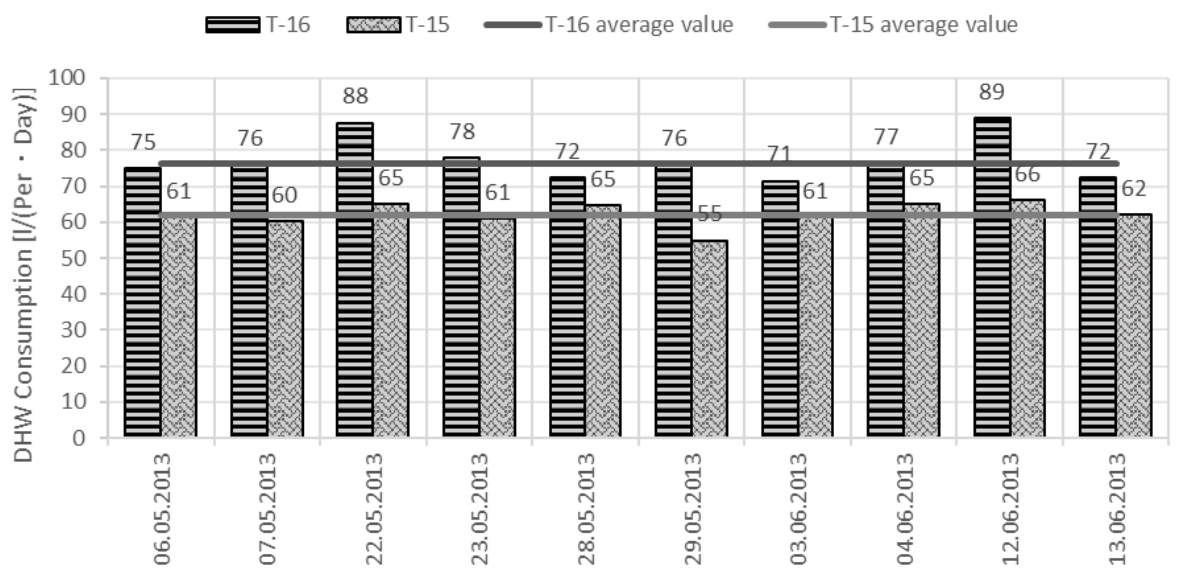

Fig. 3. The measurement carried out DHW consumption

The diagrams show that DHW consumption per person in both analysed buildings is higher than polish standard guidelines. The reason may be that the DHW temperature after the DHW heat exchanger (Fig. 4 and Fig. 5) is about $10^{\circ} \mathrm{C}$ lower than the temperature required according to the regulation [14]. The measured temperature at the point of use is about $45^{\circ} \mathrm{C}$, which entails an insignificant consumption of cold water during bathing. In addition, the DHW consumption in the T-16 building was almost twice as the normative value of DHW consumption. This is due to the lack of circulation system during the measurement period. Moreover, in the T-16 building there was no circulation system in operation during the measurement period. Higher DHW consumption in both buildings allows for greater energy savings after application GWHR. 


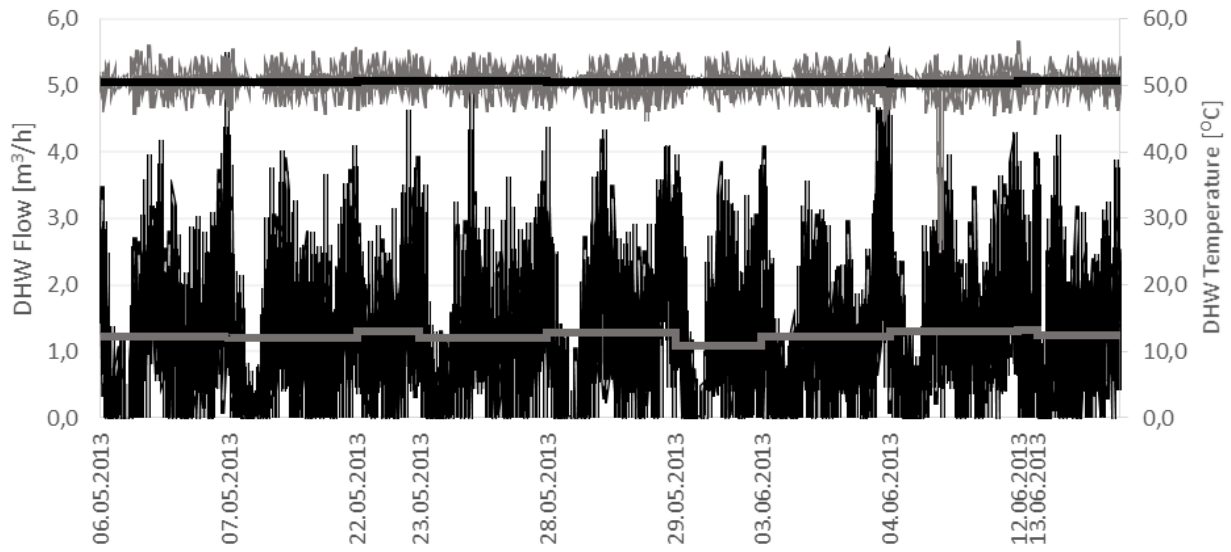

Fig. 4. The measurement carried out DHW flow rate and DHW temperature in T-15 building.

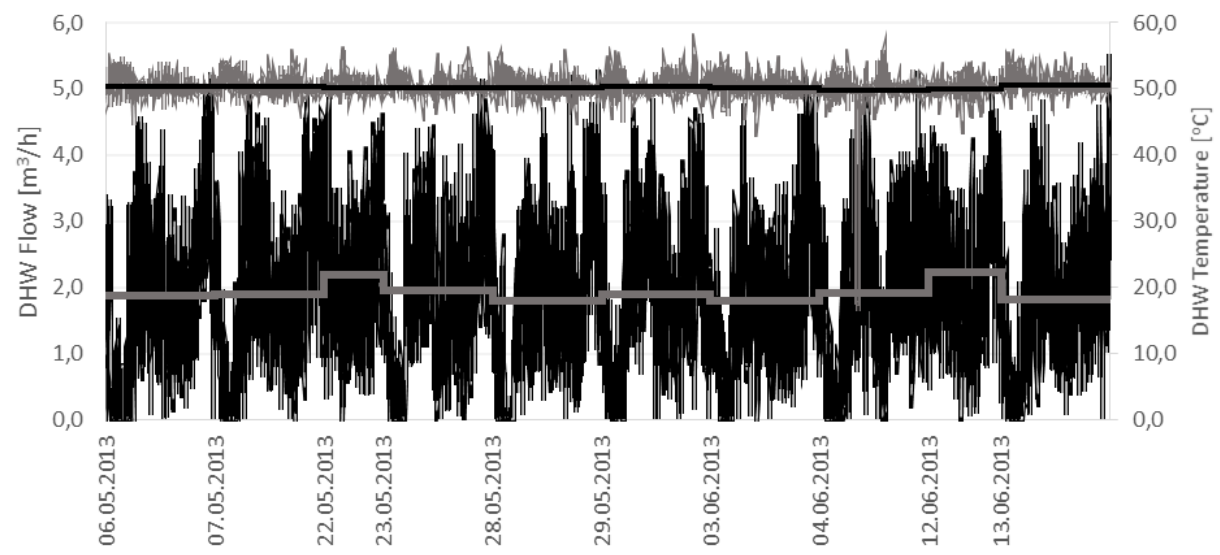

Fig. 5. The measurement carried out DHW flow rate and DHW temperature in T-16 building.

\section{Energy-saving analysis}

Based on the measurement carried out, the DHW consumption per day for the analysed buildings T-15 and T-16 is $27.6-52.8 \mathrm{~m}^{3}$. During the analysis period, it gives up to $2059 \mathrm{~m}^{3}$ of GW discharged directly to the sewage system. From the point of view of the energy required to prepare DHW, this is a large waste of heat energy.

The use of a GWHR system using a heat pump in existing students dormitories will save heat energy. Savings resulting from the use of the proposed technology were defined as the difference between the heat consumption to prepare DHW without heat recovery $\left(Q_{1}\right)$ and the heat with the heat recovery system $\left(Q_{2}\right) . \mathrm{T}_{2}$ is the temperature of DHW on the outlet of the DHW heat exchanger, $T_{1}$ is the temperature of cold water and $T_{3}$ is the temperature of the preheated water. Based on the above data, the amount of energy recovered for each building was calculated using the following formulae:

$$
\begin{aligned}
& Q_{1}=m c p\left(T_{2}-T_{1}\right) \\
& Q_{2}=m c p\left(T_{2}-T_{3}\right)
\end{aligned}
$$




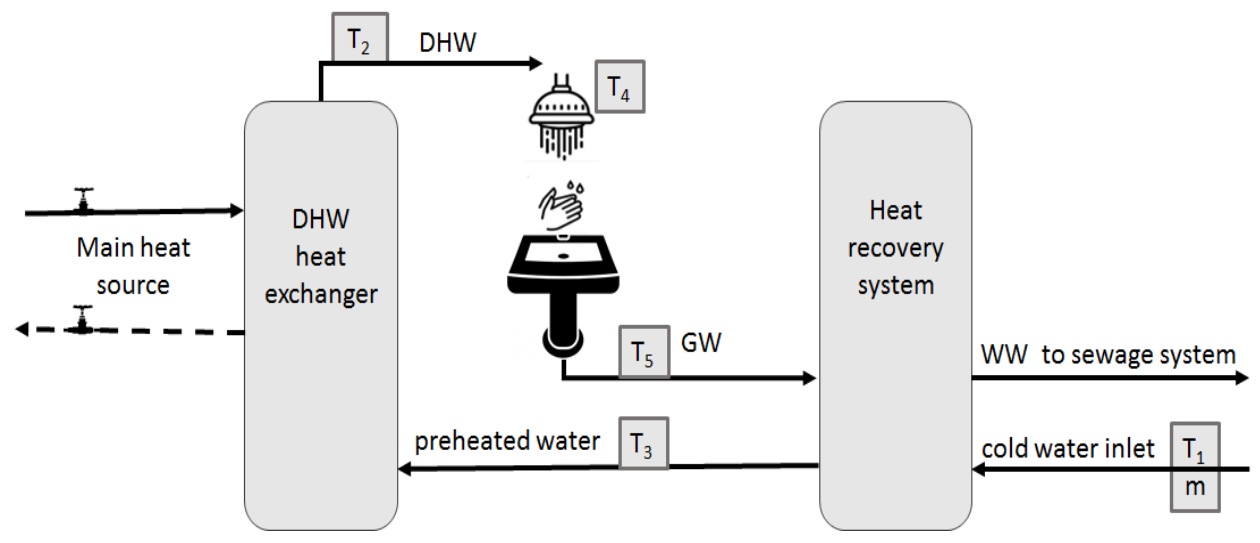

Fig. 6. Propose heat recovery system in student dormitories.

As shown Figure 6 the average temperature of cold water $\left(T_{1}\right)$ equal to $10^{\circ} \mathrm{C}$ and the temperature at the water inlet point $\left(T_{4}\right)$ equal to $40-42^{\circ} \mathrm{C}$. Therefore we can achieve the temperature of $\mathrm{GW}\left(T_{5}\right)$ at the level of $28-35^{\circ} \mathrm{C}$ [12]. The results of the energy savings analysis are presented in Table 2 and on Figure 7.

Table 2. Energy saving results from the GWHR in the analysed period.

\begin{tabular}{|c|c|c|c|c|}
\hline Student dormitory & DHW consumption & \multicolumn{2}{|c|}{ Savings [GJ] } & Savings \\
\hline & {$\left[\mathbf{m}^{3}\right]$} & min. value & max. value & {$[\%]$} \\
\hline T-15 & 1207 & 110.14 & 121.15 & 53.3 \\
\hline T-16 & 2059 & 164.28 & 205.93 & 53.3 \\
\hline
\end{tabular}

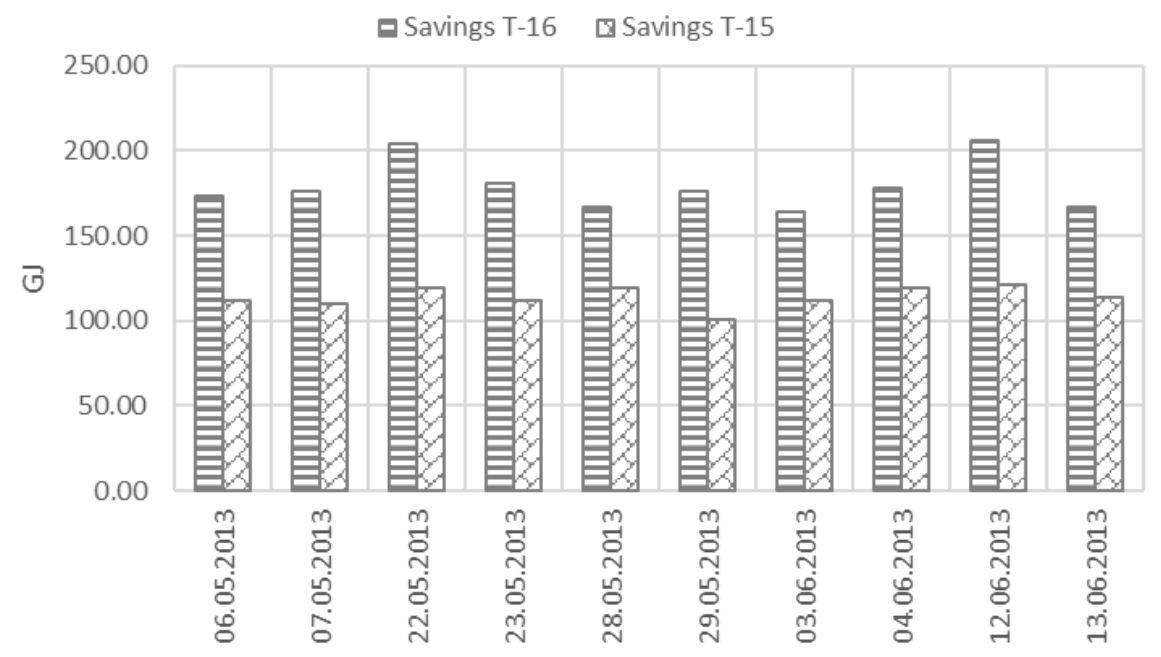

Fig. 7. The energy savings resulting in the analysed period. 


\section{Conclusions}

The analysis estimated the energy savings resulting from the use of GWHR system in relation to the total energy needed to prepare DHW in student dormitories located in Wroclaw. These savings depend on the amount of DHW consumption and on the number of people. The DHW consumption in both of analysed buildings, was almost more twice as the Polish standards. This is due to the lack of circulation system in T-16 building during the measurement period. In addition the measured temperature at the point of use is about $45^{\circ} \mathrm{C}$, which entails an insignificant consumption of cold water during bathing.

Energy savings resulting from the use of GWHR were defined as the difference between the heat consumption to prepare DHW with and without heat recovery system. An energy analysis was carried out for measurement data. Results of heat recovery from GW allows to save from 110.14 to 121.15 GJ for the T-15 and from 164.28 to 205.93 for the building $\mathrm{T}-16$, which is about (53\% of the energy needed to heat the domestic hot water) in the analysed period. Obtained savings for two buildings in such a short time allow to conclude that the use of GWHR, in this type of buildings, brings significant economic and environmental benefits. The measurement period is too short to assess the annual energy savings in these buildings, the measurements should be continued for real assessments of year around energy savings in these buildings.

The use of GWHR seeks to meet the guidelines of Directive 2018/844 of the European Parliament and of the (EU) Council of 30 May 2018 [7], which emphasizes reducing the final energy consumption.

\section{References}

1. M. A. Sayegh, M. Hammad, Z. Faraa, Energy Procedia 6, 759-768 (2011)

2. K. Bryś, T. Bryś, M. A. Sayegh, H. Ojrzyńska, Energy and Build. 165, 64-75 (2018)

3. M. A. Sayegh, P. Jadwiszczak, B. P. Axcell, E. Niemierka, K. Bryś, H. Jouhara, Energy and Buildings 166, 122-144 (2018)

4. F. Schmid, Energy-engineer FH, Swiss Energy Agency for Infrastructure Plants Gessnerallee 38a, CH-8001 Zürich, Switzerland (2008)

5. S. Kordana, D. Słyś, E3S Web of Conferences 22, 00085 (2017)

6. Y. Togano, K. Ueda, Y. Hasegawa, J. Miyamoto, T. Yamaguchi, S. Shibutani, Mitsubishi Heavy Industries Technical Review 52, 4 (2015)

7. Directive 2018/844 of the European Parliament and of the Council (EU) of 30.05. 2018

8. K. Niewitecka, E3S Web of Conferences 30, 03003 (2018)

9. E. Nowakowski, Rynek Instalacyjny 7-8, 80-82 (2012)

10. Ordinance of the Minister of Infrastructure of 14 January 2002 on the determination of the average water consumption standards (Journal of Laws No. 8 of 2002, pos. 70)

11. M. Jarosiński, M. Zarębski, Rynek Instalacyjny 6, 34 (2017)

12. Q. Zhang, X. Fan, W. Zhang, Z. Wang, Energy Procedia 142, 1244-1250 (2017)

13. P. Wichowski, D. Kadziński, D. Morawski, Przegląd Naukowy - Inżynieria i Kształtowanie środowiska 69, 236-248 (2015)

14. Ordinance of the Minister of Infrastructure of 12 April 2002 on the conditions to be met by buildings and their location (Journal of Laws No. 75 of 2002, Journal of Laws No. 33 of 2003, Journal of Laws No. 109 2004, as amended on 12.03.2009.) 